\title{
Impacts of Education and Environmental Sustainability on Rural Income Inequality in Indonesia
}

\author{
Andryan Setyadharma ${ }^{1,}{ }^{*}$, Shanty Oktavilia ${ }^{1}$, Sri Utami $^{1}$ and Audina Rizka Noormalitasari ${ }^{2}$ \\ ${ }^{1}$ Faculty of Economics, Universitas Negeri Semarang, Semarang, Indonesia \\ ${ }^{2}$ Undergraduate Program of Development Economics, Universitas Negeri Semarang, Semarang, \\ Indonesia
}

\begin{abstract}
Income inequality may hinder rural development and education is seen an important tool in rural development processes as well as it become an effective way in reducing rural income inequality. Human capital theory suggests that higher education can increase income, and it will decrease income inequality. The first objective of this study is to examine the effect of education on rural income inequality in Indonesia. This study also examines the relationship between environmental deterioration and rural income inequality. Studies about the impact of higher levels of inequality on environmental deterioration are not new, but the opposite studies are rare. Therefore, the second objective of this study is to examine the effect of environmental deterioration on rural income inequality in Indonesia. This study applies panel data from 32 provinces in Indonesia during 2012 to 2018 . The results show that higher education resulting in lower rural income inequality in Indonesia. Furthermore, the finding also shows that the efforts to reduce environmental deterioration resulting in lower rural income inequality in Indonesia. This study suggests that it is vital to improve education level and to apply nature-friendly approaches to reduce income gaps in rural areas so the rural development goals can be achieved.
\end{abstract}

\section{Introduction}

Income inequality has not been merely related to economic issue, but it also connects with social, and political issues. Income inequality do not only impede economic growth and development, but it can also create tensions between social classes, and political instability [1]. Since the impacts of income inequality is devastating, a vast number of empirical literature has been trying to identify a variety of important determinants that affect income inequality. Education has become a significant factor that impact income inequality, and so, the policymakers usually take actions by applying educational policies that are able to lower income inequalities [2]. However, education as a contributing factor of income inequality has been examined but the results have been conflicting or indecisive [1].

* Corresponding author: andryan@mail.unnes.ac.id 
The human capital theory takes place in the association between education and income inequality [3]. It is believed that the accumulation of human capital through education, training and health has been effectively reduced income inequality. A rise in the supply of educated and trained workers will lead to higher wages [4]. the education influences income distribution through two ways: first, education lowers the share of income of highest wage earners and rises the share of the lowest wage earners [1]. A research indicates than higher human capital has been remove the gap of income inequality [3].

There are other important that determine income inequality, i.e. environmental degradation [5]. There are a lot of free commodities supplied from the environment and rural families are mainly highly dependent on natural resources and exploit them to meet their subsistence needs and sell the products from nature for daily income [6]. A research by [5] indicates that poor households make a living by relying on natural resources than richer households. A survey on families in underdeveloped countries reveals that income earned from natural resources are about $28 \%$ of overall household income and $77 \%$ of which are from natural forests [6]. In addition, [6] also show that the shares of income earned from natural resources are higher for poorest households. So, there is a solid evidence that the poor is highly dependent on natural resources.

Existing literature has indicated that environmental degradation appears to be another side effect of economic inequality [5]. It is clear that the deterioration of the environmental will lead to exacerbate social and economic inequality mainly on rural people under poverty and disadvantages groups because poor people are unlikely can avoid from pollution, so it affects their healthiness and productivity which, in the end, limits their ability to earn income [5]. The degradation of natural resources has bad implication on rural people. It can potentially increase income inequality due to their inability to earn for living.

Prior empirical evidence on the impacts of education on income inequality is inconsistent, with some studies find a negative association, which means higher education are relating to lower inequality (for example [1], [2] \& [7]). while others show positive relationship between education and inequality, which means higher education are relating to higher inequality. For example, in a same study, [7] also find that the higher share of people with secondary or tertiary education is associated with higher income inequality. Different results of prior studies, particularly in respects to educational factor, suggest the importance of further studies concerning the impact of educational level on income inequality, especially in Indonesia's rural areas. Furthermore, we have shown about the importance of natural resource on rural livelihood and income generating, but only few studies try to investigate the impact of environmental degradation on income inequality. Current literature mostly focuses on the opposite way. [5] suggests that the issue about the effects of increasing income inequality level on environmental deterioration is not a new issue. Numerous studies have shown the negative impact of income inequality on environmental sustainability (see, for instances: [ $8 \& 9$ ] and many more), but there is still a question of whether environmental damage has any impact on income inequality or not.

Where the prosperity of many rural societies depends on free access to natural resources, it is also essential to increase their educational level to reduce gaps in income. Educating rural people will create to a better future for them. Better education level in rural areas can lead to many constructive results, such as reducing gap of income inequality. Analysing the impact of education and environmental sustainability on rural income inequality is vital for better understanding about the livings of rural communities. To the best of our knowledge, there is no previous study on the impact of education and environment on rural income inequality.

In addition, since the link between education and environmental degradation with income inequality is not clear, this study is trying to re-examine through empirical research its connection in rural areas of Indonesia, so the policy makers in Indonesia will not justify 
the higher level of educational attainment as an effective way to reduce rural income inequality gap without any solid evidence. As there is no previous study on the impact of education and environment on rural income inequality, this study gives a new information about impact of education and environmental sustainability on rural income inequality in Indonesia into the existing literature and to give new insight for policy makers to generate accurate policies for reducing income inequality.

\section{Literature review}

\subsection{Education and income inequality}

Human capital theory suggests that the difference on earnings depends on individuals' investment in knowledge and skills, or in other words, education and training mainly determines the distribution of earnings. Low human capital is considered as one of the key factors shaping the level of income inequality [3]. [3] add that degree of human capital embodied in individuals is a main contributing factor of their lifetime earnings. The human capital model is clear and easy to understand. The theory proposes that people should invest in education (and training) because they would increase skills and abilities which enable them to find job with high earnings and eventually a better income would raise ones' quality of life and prosperity.

The well-known concept of the impact of education on inequality is postulated by Knight and Sabot in 1983 [1]. Knight and Sabot suggest that education development has two contrasting effects, i.e. the composition effect and the wage compression effect. The composition effect occurs when an increase in the size of a group of workers with higher education will lead to wider gap of income inequality, but then the wage compression effect occurs when additional numbers of educated and skilled workers will create excess supply of educated workers. The excess supply will force the educated workers to accept lower wages to get jobs. Overall, it will reduce the wage premium and consequently reduces income inequality. These effects configurate an inverted u-shape curve similar to a concept proposed by Simon Kuznets in 1955.

\subsection{Environmental sustainability and rural income inequality}

As explained previously, researchers put more efforts to find the effects of increasing income inequality on environmental sustainability while the opposite effects are rarely discussed. Natural resources supply important goods for rural livelihoods [5], such as food, medicines, and other goods that are traded or supplied for next steps of production and provide income for rural livelihoods, known as environmental income. Environmental income refers to income generated from taking out goods from environment sources for free through simple methods and do not demanding high degree of management [6]. When environment is over-exploited, the numbers of natural capital accessible for rural people decline significantly and rural people who have high dependency on them for their daily living are impacted. Therefore, destruction of the environment, such as pollution and misuse of natural resources will reduce environmental income earned by rural communities.

[5] suggests other explanation to express the relationship between environmental sustainability and income inequality through health channel for poor people. [5] explains that poor people do not have enough equipment to protect themselves from air pollution and the air pollution clearly affects their productivity and reduce the number of workers to participate in the labour market, and as the result, more gap in income inequality between societies. [5] also suggests that reducing air pollution has side effect of reducing 
inequalities as well. Similarly, while we assume that mainly poor people reside in rural areas, [6] argues that poor people are more unprotected to air pollution and have less ways to defend themselves. Pollution affects health of the poor and health problems create difficulties for poor people to work and reduce the probability to get income, and in the end, widening income inequality.

\section{Research method}

This study estimates the impact of education and environmental sustainability on the rural income inequality in the case of rural areas in Indonesia during 2012 to 2018 . Only 32 out of 34 Provinces are included in the regression due to the availability of the data. In addition, this study also uses two other control variables, i.e. income per capita and unemployment. The dependent variable is rural income inequality, measured applying the Gini Index for rural areas, which was gathered from the Indonesia Statistics Department. The regression technique follows fixed effect of the panel data model and the empirical model is expressed as follow:

$\begin{aligned} \log (\text { Rural Gini } & \text { Index })_{i t}=\alpha_{0}+\alpha_{1} \log (\text { Average Years of Education })_{i t}+ \\ & \alpha_{2} \log (\text { Environmental Index })_{i t}+\alpha_{3} \log (\text { GRDP Per Capita })_{i t}+ \\ & \alpha_{3} \log (G R D P \text { Per Capita })^{2}{ }_{i t} \alpha_{4}\left({\text { Unemployment Level })_{i t}+}_{+} u_{i t}\right.\end{aligned}$ (1)

Where, $L O G$ indicates the logarithm, $u$ is the disturbance, the subscripts $i$ and $t$ are provinces for cross section and periods of time, respectively. $\alpha_{0}$ is a constant, $\alpha_{1}, \alpha_{2}, \alpha_{3}, \alpha_{4}$ are the parameters. The first control variable is education and is measured by average years of schooling data provided by the Indonesia Statistics Department. The second control variable is using Environmental Index (EI) at provincial level as the variable for the environmental sustainability. The data are retrieved from the Government office of Environment and Forestry. The dataset of EI Index (with a range of 0 up to 100, where 0 is the worst and 100 is the best quality of environment). The third control variable is income per capita measured using Gross Domestic Regional Product (GRDP) Per Capita in constant price from the Indonesia Statistics Department. The use of square term of GRDP Per Capita is to test the existence of Kuznets Curve hypothesis suggested by Simon Kuznets. The fifth control variable is unemployment, proxied by unemployment rate data obtained from the Indonesia Statistics Department.

\section{Result and discussion}

It is important to choose the ideal model in panel data method. There are three types of panel data, i.e., Common Effect Model (CEM), Fixed Effect Model (REM) and Random Effect Model (REM) and the finest model is selected over three tests: Chow test, Lagrange Multiplier (LM) test and Hausman test. This study has followed steps to choose the best model, and it is concluded that the appropriate model is fixed effect model (FEM). As indicated in Table 1, two out of three tests imply that FEM is the best model. 
Table 1. The Result of the Selection of Best Model

\begin{tabular}{|c|l|l|}
\hline \multicolumn{1}{|c|}{ Tests } & F-Stat Values & \multicolumn{1}{c|}{ Hypotheses and Results } \\
\hline \multirow{3}{*}{ Chow Test } & $21.17^{* * *}$ & $\begin{array}{l}\left.\mathrm{H}_{0}: \text { CEM is the better model (if } p \text {-value }>0.10\right) \\
\left.\mathrm{H}_{1}: \text { FEM is the better model (if } p \text {-value }<0.10\right) \\
\text { Result: } \mathrm{H}_{\mathrm{o}} \text { is declined, so FEM is selected }\end{array}$ \\
\hline \multirow{3}{*}{ LM Test } & $319.63^{* * *}$ & $\begin{array}{l}\left.\mathrm{H}_{0}: \text { CEM is the better model (if } p \text {-value }>0.10\right) \\
\mathrm{H} 1: \mathrm{REM} \text { is the better model (if } p \text {-value }<0.10) \\
\text { Result: } \mathrm{H}_{\mathrm{o}} \text { is declined, so REM is selected }\end{array}$ \\
\hline \multirow{2}{*}{ Hausman Test } & $139.32^{* *}$ & $\begin{array}{l}\left.\mathrm{H}_{0}: \mathrm{REM} \text { is the better model (if } p \text {-value }>0.10\right) \\
\left.\mathrm{H}_{1}: \mathrm{FEM} \text { is the better model (if } p \text {-value }<0.10\right) \\
\text { Result: } \mathrm{H}_{\mathrm{o}} \text { is declined, so FEM is selected }\end{array}$ \\
\hline Decision & $\begin{array}{l}\text { Two out of three tests select FEM as the best model. Overall, it is concluded } \\
\text { that FEM is the best model }\end{array}$ \\
\hline
\end{tabular}

Note: $* * *$ indicates significant at $p \leq 0.01 ; * *$ significant at $p \leq 0.05$.

The model is weighted with White cross-section standard errors \& covariance procedure to diminish heteroscedasticity issues. Table 2 shows the result of the fixed effect model. From the estimation result in Table 2, we can see that the value of Adjusted $R^{2}$ is 0.754 which means that $75.4 \%$ of the variation in the rural income inequality variable can be justified by the variation of education, environmental sustainability, income per capita and unemployment variables, and the remain $24.6 \%$ of the variation is described by other variables not in the model.

Table 2. Output of the Panel Data

\begin{tabular}{|l|c|c|c|}
\hline Explanatory Variables & Coefficients & t-statistics & $p$-values \\
\hline $\begin{array}{l}\text { Log of Average Years of } \\
\text { Education }\end{array}$ & -0.100 & -3.314 & 0.001 \\
\hline $\begin{array}{l}\text { Log of Environmental } \\
\text { Index }\end{array}$ & -0.125 & -2.285 & 0.023 \\
\hline $\begin{array}{l}\text { Log of GRDP Per } \\
\text { Capita }\end{array}$ & 2.420 & 2.558 & 0.011 \\
\hline $\begin{array}{l}\text { Log of GRDP Per } \\
\text { Capita Squared }\end{array}$ & -0.124 & -2.784 & 0.006 \\
\hline $\begin{array}{l}\text { Unemployment Rate } \\
\text { Constant }\end{array}$ & -0.0004 & -0.090 & 0.928 \\
\hline Adjusted R & -12.120 & -2.339 & 0.020 \\
\hline
\end{tabular}

Note: Explained Variable: Ln (Rural GINI Index)

Four out of five control variables (average years of education, environmental index, GRDP per capita and GRDP per capita squared) are statistically significant. The panel data outcome in table 2 indicates that the regression coefficient that represents the education variable, average years of education has negative sign, which indicates that a rise in average years of education is significantly reducing the Rural Gini Index. So, it can be concluded that higher education attainment successfully reduces the rural income inequality in Indonesia. This study is in line with previous studies such as [1], [2] \& [7]. The result supports the Human Capital theory, where the higher education level means more probability to get decent jobs with higher salaries or wages, and in the end, improve 
individual's quality of life and prosperity and shorten the income inequality between individuals in rural areas.

The regression coefficient of the environmental sustainability variable, the environmental index is also a negative value, which implies that higher environmental index (better quality of environment) is associated with the reduction of the Rural Gini Index. The result indicates that higher environmental quality effectively reduces the rural income inequality in Indonesia. While the previous studies, such as [8 \& 9], indicate the negative impact of income inequality on environmental sustainability, this study shows the opposite way, where higher environmental sustainability is associated with lower rural income inequality. This study also supports previous study by [5]. The preservation of the environment increases the ability of natural resources to supply essential goods for rural peoples and it can provide environmental income for rural livelihoods. When environment is maintained, the numbers of natural capital available for rural people improves significantly and rural communities will earn more environmental income, and in the end, it reduces the income inequality between people in rural areas. In short, when the accessibility of natural capital for rural communities increases, rural income inequality appears to drop.

Furthermore, the parameter associated between GRDP Per Capita variable with Rural Gini Index variable is positive and significant, while the parameter associated between GRDP Per Capita squared variable with Rural Gini Index variable is negative and significant. The results suggest that the existence of Kuznets Curve Hypothesis is confirmed in this study. Kuznets Curve Hypothesis posits that at the first stage of development, inequality is increasing when income is increasing and at a certain point, inequality is decreasing with the increase of the income. In this study, the positive sign of GRDP Per Capita variable implies that higher GRDP Per Capita is correlated with higher Rural Gini Index, confirming the first stage of Kuznets Curve Hypothesis. Then, the second variable, i.e. GRDP Per Capita squared variable, has negative relationship with Rural Gini Index, confirming the second stage of Kuznets Curve Hypothesis. In conclusion, this study confirms the existence of Kuznets Curve Hypothesis, suggested by Simon Kuznets in 1955. While the finding seems as expected, this variable has a limitation. The limitation of the income per capita variable used in this study is that it is measured by GRDP Per Capita in provincial level, not specifically rural income per capita.

Only one explanatory variable in this study is not statistically significant. It seems that unemployment level variable has no relationship with Rural Gini Index variable. So, the result is contradicted with previous study by [10]. The reason of this insignificant result seems due to being the unemployed people in rural areas does not mean they have higher probability of ending up with low income. Unemployed rural villagers can still earn environmental income from natural resources.

\section{Conclusion and policy implications}

This study investigates in what way education and environmental sustainability may have significant consequences on rural income inequality in Indonesia. Using panel data method with fixed effect model from 32 provinces in Indonesia during 2012 to 2018, this study finds the negative relationship where higher education and better environmental quality reduce the rural income inequality in Indonesia. As of a policy standpoint, this study leads to valuable insights in the efforts to tackle rural income inequality. The significant impacts of education and environmental sustainability on rural income inequality emphasise the needs to expand the access to the education for rural people and the importance of the preservation of the environment to create secure access for rural communities to earn environmental income from natural resources. 


\section{References}

1. A. Abdullah, H. Doucouliagos, E Manning, J. of Eco Surv. 29, 301-316 (2013)

2. D. Checchi, H.G. van de Werfhorst, Discussion Paper No. 8222 (Bonn, The Institute for the Study of Labor (IZA), 2014)

3. J.W. Lee, H. Lee, Human Capital and Income Inequality (Tokyo, Asian Development Bank Institute, 2018)

4. S. Kampelmann, F. Rycx, Y. Saks, I. Tojerow, IZA J. Labor Econ. 7, 1- 37 (2018)

5. United Nations Economic and Social Commission for Asia and the Pacific, Inequality in asia and the pacific in the era of the 2030 agenda for sustainable development (Bangkok Thailand, United Nations, 2018)

6. A. Angelsen, P. Jagger, R. Babigumira, B. Belcher, H.J. Hogarth, S. Bauch, J. Borner, C. Smith-Hall, S. Wunder, World Dev. 64, S12-S28. (2014).

7. F. Jaumotte, S. Lall, C. Papageorgiou. IMF Econ. Rev. 61, 271-309. (2013).

8. M.M. Masud, F.B. Kari, H. Banna \& M.K. Saifull, J. of the Aspac Eco. 23, 213-228. (2018)

9. D. Dorling, Envir. Scientist. 19, 9-13 (2010).

10. N. P. R. Deyshappriya, ADBI Working Paper, No. 696 (Tokyo, Asian Development Bank Institute 2017) 


\section{Appendix}

\begin{tabular}{|c|c|c|c|c|c|}
\hline $\begin{array}{l}\text { Provincial } \\
\text { Code }\end{array}$ & $\begin{array}{l}\text { Rural Gini } \\
\text { Index }\end{array}$ & $\begin{array}{l}\text { Average Years } \\
\text { of education }\end{array}$ & $\begin{array}{l}\text { Environmental } \\
\text { Index }\end{array}$ & $\begin{array}{l}\text { GRDP per } \\
\text { capita }\end{array}$ & $\begin{array}{c}\text { Unemployment } \\
\text { level }\end{array}$ \\
\hline $1-12$ & 0.26 & 8.36 & 73.06 & 23099.13 & 9.06 \\
\hline $1-13$ & 0.254 & 8.72 & 71.72 & 23228.59 & 10.12 \\
\hline $1-14$ & 0.277 & 8.27 & 72.6 & 23129.04 & 9.02 \\
\hline $1-15$ & 0.293 & 8.34 & 72.6 & 22524.31 & 9.93 \\
\hline $1-16$ & 0.296 & 7.69 & 73.55 & 22835.29 & 7.57 \\
\hline $1-17$ & 0.299 & 7.5 & 77.7 & 23362.9 & 6.57 \\
\hline $1-18$ & 0.273 & 9.09 & 79.36 & 24013.81 & 6.36 \\
\hline $2-12$ & 0.294 & 8.01 & 62.71 & 28036.88 & 6.28 \\
\hline $2-13$ & 0.281 & 7.3 & 62.9 & 29339.21 & 6.45 \\
\hline $2-14$ & 0.282 & 7.25 & 61.53 & 30477.07 & 6.23 \\
\hline $2-15$ & 0.285 & 9.58 & 61.53 & 31637.41 & 6.71 \\
\hline $2-16$ & 0.27 & 10.43 & 66.47 & 32885.09 & 5.84 \\
\hline $2-17$ & 0.264 & 7.52 & 69.77 & 34183.58 & 5.6 \\
\hline $2-18$ & 0.257 & 9.34 & 64.41 & 35570.71 & 5.56 \\
\hline $3-12$ & 0.321 & 6.77 & 69.8 & 23744.01 & 6.65 \\
\hline $3-13$ & 0.288 & 8.63 & 67.79 & 24857.64 & 7.02 \\
\hline $3-14$ & 0.28 & 6.85 & 68.91 & 25982.83 & 6.5 \\
\hline $3-15$ & 0.28 & 8.06 & 68.91 & 27080.76 & 6.89 \\
\hline $3-16$ & 0.267 & 8.05 & 60.06 & 28164.93 & 5.09 \\
\hline $3-17$ & 0.288 & 6.33 & 68.16 & 29310.69 & 5.58 \\
\hline $3-18$ & 0.262 & 8.76 & 78.69 & 30470.63 & 5.55 \\
\hline $4-12$ & 0.332 & 6.71 & 52.12 & 72396.34 & 4.37 \\
\hline $4-13$ & 0.323 & 6.62 & 50.72 & 72297.05 & 5.48 \\
\hline $4-14$ & 0.324 & 7.73 & 52.59 & 72390.88 & 6.56 \\
\hline $4-15$ & 0.33 & 7.48 & 52.59 & 70769.78 & 7.83 \\
\hline $4-16$ & 0.309 & 8.83 & 56.73 & 70569.36 & 7.43 \\
\hline $4-17$ & 0.299 & 8.71 & 68.64 & 70755.18 & 6.22 \\
\hline $4-18$ & 0.292 & 8.92 & 68.43 & 70740.08 & 6.2 \\
\hline $5-12$ & 0.322 & 7.73 & 61.36 & 32417.72 & 3.2 \\
\hline $5-13$ & 0.296 & 7.37 & 59.77 & 34012.1 & 4.76 \\
\hline $5-14$ & 0.321 & 7.76 & 62.04 & 35878.09 & 5.08 \\
\hline $5-15$ & 0.319 & 6.92 & 62.04 & 36753.52 & 4.34 \\
\hline $5-16$ & 0.292 & 6.76 & 64.01 & 37728.8 & 4 \\
\hline $5-17$ & 0.295 & 8.8 & 64.98 & 38849.52 & 3.87 \\
\hline $5-18$ & 0.295 & 8.23 & 71 & 40051.65 & 3.86 \\
\hline $6-12$ & 0.341 & 8.04 & 56.73 & 28577.89 & 5.66 \\
\hline $6-13$ & 0.318 & 6.87 & 59.1 & 29656.76 & 4.84 \\
\hline $6-14$ & 0.317 & 5.73 & 61.62 & 30636.27 & 4.96 \\
\hline $6-15$ & 0.286 & 8.44 & 61.62 & 31549.3 & 6.07 \\
\hline $6-16$ & 0.306 & 8.79 & 67.27 & 32699.5 & 4.31 \\
\hline $6-17$ & 0.328 & 8.28 & 69.18 & 34059.71 & 4.39 \\
\hline $6-18$ & 0.296 & 8 & 68.11 & 35670 & 4.23 \\
\hline $7-12$ & 0.322 & 8.38 & 65.66 & 18143.51 & 3.62 \\
\hline $7-13$ & 0.326 & 7.8 & 67.53 & 18919.3 & 4.61 \\
\hline $7-14$ & 0.33 & 7.53 & 66.76 & 19626.72 & 3.47 \\
\hline
\end{tabular}




\begin{tabular}{|c|c|c|c|c|c|}
\hline $7-15$ & 0.338 & 8.09 & 66.76 & 20302.48 & 4.91 \\
\hline $7-16$ & 0.296 & 7.32 & 72.43 & 21039.84 & 3.3 \\
\hline $7-17$ & 0.317 & 7.32 & 70.18 & 21751.64 & 3.74 \\
\hline $7-18$ & 0.316 & 8.61 & 74.32 & 22498.43 & 3.51 \\
\hline $8-12$ & 0.32 & 9.63 & 51.9 & 21794.83 & 5.2 \\
\hline $8-13$ & 0.291 & 10.47 & 54.72 & 22770.68 & 5.69 \\
\hline $8-14$ & 0.283 & 7.58 & 56.42 & 23647.27 & 4.79 \\
\hline $8-15$ & 0.313 & 6.8 & 56.42 & 24581.78 & 5.14 \\
\hline $8-16$ & 0.311 & 8.72 & 60.34 & 25568.57 & 4.62 \\
\hline $8-17$ & 0.301 & 6.9 & 59.72 & 26614.82 & 4.33 \\
\hline $8-18$ & 0.294 & 7.82 & 59.89 & 27742.03 & 4.06 \\
\hline $9-12$ & 0.285 & 8.17 & 57.73 & 31172.42 & 3.43 \\
\hline $9-13$ & 0.239 & 8.1 & 59.29 & 32081.3 & 3.65 \\
\hline $9-14$ & 0.252 & 6.54 & 60.21 & 32859.64 & 5.14 \\
\hline $9-15$ & 0.259 & 6.76 & 60.21 & 33480.38 & 6.29 \\
\hline $9-16$ & 0.239 & 6.69 & 66.88 & 34132.87 & 2.6 \\
\hline $9-17$ & 0.236 & 7.79 & 67.85 & 34934.71 & 3.78 \\
\hline $9-18$ & 0.222 & 7.84 & 67.68 & 35764.82 & 3.65 \\
\hline $10-12$ & 0.315 & 7.59 & 66.59 & 70930 & 5.08 \\
\hline $10-13$ & 0.305 & 8.87 & 67.26 & 73743.33 & 5.63 \\
\hline $10-14$ & 0.31 & 8.79 & 69.27 & 76313.81 & 6.69 \\
\hline $10-15$ & 0.283 & 7.82 & 69.27 & 78625.43 & 6.2 \\
\hline $10-16$ & 0.264 & 7.45 & 70.19 & 80295.6 & 7.69 \\
\hline $10-17$ & 0.286 & 7.93 & 70.34 & 79757.93 & 7.16 \\
\hline $10-18$ & 0.262 & 9.81 & 66.5 & 81295.31 & 7.12 \\
\hline $12-12$ & 0.293 & 8.71 & 48.37 & 23036 & 9.08 \\
\hline $12-13$ & 0.299 & 8.93 & 47.8 & 24118.31 & 9.16 \\
\hline $12-14$ & 0.294 & 8.29 & 45.06 & 24966.86 & 8.45 \\
\hline $12-15$ & 0.31 & 8.47 & 45.06 & 25845.5 & 8.72 \\
\hline $12-16$ & 0.31 & 7.92 & 51.87 & 26923.51 & 8.89 \\
\hline $12-17$ & 0.326 & 7.66 & 50.26 & 27975.13 & 8.22 \\
\hline $12-18$ & 0.315 & 8.15 & 56.98 & 29161.39 & 8.17 \\
\hline $13-12$ & 0.319 & 8.28 & 60.05 & 20950.62 & 5.61 \\
\hline $13-13$ & 0.359 & 7.48 & 58 & 21844.87 & 6.01 \\
\hline $13-14$ & 0.359 & 7.35 & 60.63 & 22819.16 & 5.68 \\
\hline $13-15$ & 0.344 & 9.64 & 60.63 & 23887.06 & 4.99 \\
\hline $13-16$ & 0.313 & 10.54 & 58.75 & 24959.49 & 4.63 \\
\hline $13-17$ & 0.323 & 7.71 & 58.15 & 26088.91 & 4.57 \\
\hline $13-18$ & 0.315 & 7.35 & 68.27 & 27290.82 & 4.51 \\
\hline $14-12$ & 0.392 & 6.93 & 53.03 & 20183.88 & 3.9 \\
\hline $14-13$ & 0.343 & 8.84 & 51.81 & 21037.7 & 3.24 \\
\hline $14-14$ & 0.378 & 7.05 & 49.53 & 21867.9 & 3.33 \\
\hline $14-15$ & 0.332 & 8.19 & 49.53 & 22688.36 & 4.07 \\
\hline $14-16$ & 0.343 & 8.11 & 51.37 & 23565.68 & 2.72 \\
\hline $14-17$ & 0.317 & 6.67 & 49.8 & 24534.27 & 3.02 \\
\hline $14-18$ & 0.326 & 9.32 & 62.98 & 25776.98 & 3.35 \\
\hline $15-12$ & 0.268 & 6.85 & 57.61 & 29508.4 & 4.11 \\
\hline $15-13$ & 0.309 & 6.83 & 56.25 & 31092.04 & 4.3 \\
\hline $15-14$ & 0.339 & 7.82 & 56.48 & 32703.39 & 4.19 \\
\hline $15-15$ & 0.327 & 7.6 & 56.48 & 34271.81 & 4.47 \\
\hline
\end{tabular}




\begin{tabular}{|c|c|c|c|c|c|}
\hline $15-16$ & 0.313 & 9.04 & 58.98 & 35970.78 & 4.21 \\
\hline $15-17$ & 0.317 & 8.86 & 57.46 & 37724.29 & 4 \\
\hline $15-18$ & 0.322 & 7.39 & 67.08 & 39587.92 & 3.99 \\
\hline $16-12$ & 0.308 & 7.89 & 46.85 & 27716.47 & 9.94 \\
\hline $16-13$ & 0.276 & 7.49 & 46.33 & 28910.66 & 9.54 \\
\hline $16-14$ & 0.294 & 8.02 & 43.67 & 29846.64 & 9.07 \\
\hline $16-15$ & 0.261 & 6.97 & 43.67 & 30813.03 & 9.55 \\
\hline $16-16$ & 0.248 & 6.88 & 60 & 31781.56 & 8.92 \\
\hline $16-17$ & 0.27 & 9.15 & 51.58 & 32940.28 & 9.28 \\
\hline $16-18$ & 0.299 & 8.62 & 57 & 34191.75 & 8.52 \\
\hline $17-12$ & 0.346 & 8.34 & 59.11 & 26689.58 & 2.1 \\
\hline $17-13$ & 0.384 & 6.96 & 57.5 & 28129.67 & 1.83 \\
\hline $17-14$ & 0.337 & 5.76 & 59.81 & 29668.9 & 1.9 \\
\hline $17-15$ & 0.35 & 8.77 & 59.81 & 31093.61 & 1.99 \\
\hline $17-16$ & 0.335 & 9.03 & 72.59 & 32689.09 & 1.89 \\
\hline $17-17$ & 0.302 & 8.42 & 70.11 & 34132.52 & 1.48 \\
\hline $17-18$ & 0.31 & 8.65 & 66.62 & 35914.6 & 1.37 \\
\hline $18-12$ & 0.312 & 8.49 & 67.57 & 14276.69 & 5.23 \\
\hline $18-13$ & 0.281 & 7.96 & 67.77 & 14809.84 & 5.3 \\
\hline $18-14$ & 0.306 & 7.77 & 69.39 & 15369.94 & 5.75 \\
\hline $18-15$ & 0.342 & 8.29 & 69.39 & 18475.14 & 5.69 \\
\hline $18-16$ & 0.306 & 7.56 & 56.53 & 19305.79 & 3.94 \\
\hline $18-17$ & 0.323 & 7.46 & 56.99 & 19097.58 & 3.32 \\
\hline $18-18$ & 0.343 & 7.03 & 75.16 & 18015.37 & 3.72 \\
\hline $19-12$ & 0.285 & 9.65 & 66.9 & 10030.98 & 3.04 \\
\hline $19-13$ & 0.255 & 10.7 & 64.19 & 10396.76 & 3.25 \\
\hline $19-14$ & 0.281 & 7.86 & 62.98 & 10742.32 & 3.26 \\
\hline $19-15$ & 0.303 & 7.03 & 62.98 & 11087.91 & 3.83 \\
\hline $19-16$ & 0.317 & 9 & 59.23 & 11468.79 & 3.25 \\
\hline $19-17$ & 0.309 & 7.14 & 61.92 & 11863.28 & 3.27 \\
\hline $19-18$ & 0.327 & 7.3 & 69.01 & 12276.12 & 3.01 \\
\hline $20-12$ & 0.321 & 8.27 & 69.91 & 21062.22 & 3.54 \\
\hline $20-13$ & 0.302 & 8.26 & 68.12 & 21971.93 & 3.99 \\
\hline $20-14$ & 0.356 & 6.71 & 68.31 & 22712.65 & 4.04 \\
\hline $20-15$ & 0.286 & 6.93 & 68.31 & 23456.52 & 5.15 \\
\hline $20-16$ & 0.275 & 6.93 & 72.24 & 24308.85 & 4.23 \\
\hline $20-17$ & 0.285 & 8.03 & 74.17 & 25199.06 & 4.36 \\
\hline $20-18$ & 0.278 & 7.12 & 73.09 & 26108.13 & 4.26 \\
\hline $21-12$ & 0.279 & 7.76 & 70.84 & 27749.01 & 3.14 \\
\hline $21-13$ & 0.3 & 9.15 & 69.53 & 29106.4 & 3 \\
\hline $21-14$ & 0.327 & 8.88 & 70.37 & 30216.73 & 3.24 \\
\hline $21-15$ & 0.268 & 7.97 & 70.37 & 31619.18 & 4.54 \\
\hline $21-16$ & 0.326 & 7.64 & 74.71 & 32899.58 & 4.82 \\
\hline $21-17$ & 0.303 & 8.18 & 71.47 & 34369.21 & 4.23 \\
\hline $21-18$ & 0.318 & 8.37 & 75.71 & 35559.52 & 4.01 \\
\hline $22-12$ & 0.309 & 7.05 & 57.1 & 25547.77 & 5.19 \\
\hline $22-13$ & 0.265 & 6.94 & 56.2 & 26423.9 & 3.66 \\
\hline $22-14$ & 0.293 & 9.16 & 57.51 & 27220.27 & 3.8 \\
\hline $22-15$ & 0.282 & 8.37 & 57.51 & 27786.68 & 4.92 \\
\hline $22-16$ & 0.298 & 7.01 & 59.07 & 28540.05 & 5.45 \\
\hline
\end{tabular}




\begin{tabular}{|c|c|c|c|c|c|}
\hline $22-17$ & 0.285 & 5.99 & 69.38 & 29578.12 & 4.77 \\
\hline $22-18$ & 0.279 & 8 & 68.78 & 30627.71 & 4.5 \\
\hline $23-12$ & 0.3 & 8.86 & 73.12 & 124501.9 & 9.02 \\
\hline $23-13$ & 0.283 & 9.12 & 72.41 & 133868.7 & 7.95 \\
\hline $23-14$ & 0.295 & 8.59 & 74 & 133086.1 & 7.38 \\
\hline $23-15$ & 0.273 & 8.59 & 74 & 128603.1 & 7.5 \\
\hline $23-16$ & 0.313 & 8.07 & 76.85 & 125385.5 & 7.95 \\
\hline $23-17$ & 0.28 & 7.83 & 75.65 & 126625.2 & 6.91 \\
\hline $23-18$ & 0.297 & 9.48 & 85.9 & 127389.6 & 6.6 \\
\hline $24-12$ & 0.383 & 8.37 & 65.75 & 25145.96 & 7.98 \\
\hline $24-13$ & 0.385 & 7.63 & 63.57 & 26445.86 & 6.79 \\
\hline $24-14$ & 0.366 & 7.62 & 65.69 & 27805.52 & 7.54 \\
\hline $24-15$ & 0.345 & 9.67 & 65.69 & 29196.47 & 9.03 \\
\hline $24-16$ & 0.35 & 10.88 & 67.07 & 30679.97 & 6.18 \\
\hline $24-17$ & 0.346 & 7.95 & 70.81 & 32297.67 & 7.18 \\
\hline $24-18$ & 0.368 & 9.24 & 74.95 & 33915.22 & 6.86 \\
\hline $25-12$ & 0.337 & 7.15 & 79.98 & 22724.47 & 3.95 \\
\hline $25-13$ & 0.325 & 9.12 & 78.46 & 24490.98 & 4.19 \\
\hline $25-14$ & 0.283 & 7.23 & 76.4 & 25316.27 & 3.68 \\
\hline $25-15$ & 0.303 & 8.37 & 76.4 & 28778.64 & 4.1 \\
\hline $25-16$ & 0.308 & 8.36 & 68.78 & 31151.08 & 3.29 \\
\hline $25-17$ & 0.313 & 6.79 & 73.24 & 32860.48 & 3.81 \\
\hline $25-18$ & 0.28 & 8.52 & 83.34 & 34419.41 & 3.43 \\
\hline $26-12$ & 0.378 & 7.02 & 64.76 & 24507.17 & 6.01 \\
\hline $26-13$ & 0.365 & 6.98 & 63.58 & 26083.42 & 5.1 \\
\hline $26-14$ & 0.429 & 8.13 & 64.06 & 27749.47 & 5.08 \\
\hline $26-15$ & 0.346 & 7.89 & 64.06 & 29435.92 & 5.95 \\
\hline $26-16$ & 0.34 & 9.24 & 70.54 & 31302.53 & 4.8 \\
\hline $26-17$ & 0.332 & 8.96 & 69.39 & 33234.11 & 5.61 \\
\hline $26-18$ & 0.353 & 8.02 & 74.83 & 35253.61 & 5.34 \\
\hline $27-12$ & 0.358 & 8.12 & 70.32 & 25489.79 & 4.14 \\
\hline $27-13$ & 0.332 & 7.75 & 68.71 & 26815.36 & 4.38 \\
\hline $27-14$ & 0.36 & 8.32 & 72.14 & 27896.05 & 4.43 \\
\hline $27-15$ & 0.355 & 7.12 & 72.14 & 29202.7 & 5.55 \\
\hline $27-16$ & 0.352 & 7.14 & 75.24 & 30476.39 & 2.72 \\
\hline $27-17$ & 0.373 & 9.27 & 70.86 & 31894.47 & 3.3 \\
\hline $27-18$ & 0.356 & 8.69 & 83.17 & 33285.62 & 3.26 \\
\hline $28-12$ & 0.419 & 8.52 & 74.69 & 16650.27 & 4.47 \\
\hline $28-13$ & 0.428 & 7.06 & 74.19 & 17639.12 & 4.15 \\
\hline $28-14$ & 0.444 & 6.15 & 75.52 & 18622.44 & 4.18 \\
\hline $28-15$ & 0.366 & 8.98 & 75.52 & 19474.13 & 4.65 \\
\hline $28-16$ & 0.397 & 9.25 & 69.3 & 20427.46 & 2.76 \\
\hline $28-17$ & 0.379 & 8.72 & 67.46 & 21477.97 & 4.28 \\
\hline $28-18$ & 0.413 & 7.46 & 84.09 & 22541.35 & 4.03 \\
\hline $29-12$ & 0.276 & 8.76 & 71.45 & 17169.06 & 2.16 \\
\hline $29-13$ & 0.295 & 8.15 & 70.14 & 18008.81 & 2.35 \\
\hline $29-14$ & 0.344 & 7.99 & 72.29 & 19232.05 & 2.08 \\
\hline $29-15$ & 0.339 & 8.47 & 72.29 & 20250.51 & 3.35 \\
\hline $29-16$ & 0.341 & 7.79 & 64.54 & 21067.91 & 3.33 \\
\hline $29-17$ & 0.299 & 7.78 & 74.47 & 22049.63 & 3.21 \\
\hline
\end{tabular}




\begin{tabular}{|r|r|r|r|r|r|}
\hline $29-18$ & 0.311 & 7.5 & 79.89 & 22999.15 & 3.16 \\
\hline $30-12$ & 0.328 & 9.79 & 74.34 & 13129.11 & 7.71 \\
\hline $30-13$ & 0.286 & 11.02 & 73.78 & 13572.07 & 9.91 \\
\hline $30-14$ & 0.293 & 8.14 & 74.79 & 14219.62 & 10.51 \\
\hline $30-15$ & 0.307 & 7.27 & 74.79 & 14740.38 & 9.93 \\
\hline $30-16$ & 0.303 & 9.19 & 71.66 & 15321.18 & 7.05 \\
\hline $30-17$ & 0.29 & 7.34 & 75.12 & 15942.39 & 9.29 \\
\hline $30-18$ & 0.288 & 9.58 & 81.23 & 16611.66 & 7.27 \\
\hline $31-12$ & 0.251 & 8.53 & 79.31 & 15691.01 & 4.82 \\
\hline $31-13$ & 0.266 & 8.55 & 77.47 & 16332.22 & 3.8 \\
\hline $31-14$ & 0.264 & 6.9 & 77.22 & 16869.52 & 5.29 \\
\hline $31-15$ & 0.256 & 7.15 & 77.22 & 17533.78 & 6.05 \\
\hline $31-16$ & 0.251 & 7.05 & 72.46 & 18177.3 & 4.01 \\
\hline $31-17$ & 0.277 & 8.29 & 74.55 & 19192.97 & 5.33 \\
\hline $31-18$ & 0.277 & 8.72 & 88.25 & 20322.46 & 4.77 \\
\hline $32-12$ & 0.357 & 7.99 & 83.5 & 55047.84 & 5.42 \\
\hline $32-13$ & 0.364 & 9.36 & 83.45 & 57581.36 & 4.4 \\
\hline $32-14$ & 0.355 & 9.14 & 84.51 & 59142.59 & 5.02 \\
\hline $32-15$ & 0.461 & 8.29 & 84.51 & 60064.13 & 8.08 \\
\hline $32-16$ & 0.394 & 7.95 & 83.01 & 61242.01 & 7.46 \\
\hline $32-17$ & 0.386 & 8.46 & 85.69 & 62164.13 & 6.49 \\
\hline $32-18$ & 0.427 & 7.27 & 91.5 & 64486.69 & 6.3 \\
\hline $33-12$ & 0.372 & 7.28 & 82.55 & 36280.03 & 3.71 \\
\hline $33-13$ & 0.354 & 7.31 & 82.98 & 38621.36 & 3.15 \\
\hline $33-14$ & 0.384 & 9.38 & 80.65 & 39271.88 & 3.44 \\
\hline $33-15$ & 0.387 & 8.61 & 80.65 & 41376.97 & 3.99 \\
\hline $33-16$ & 0.392 & 7.15 & 81.35 & 44342.14 & 3.35 \\
\hline $33-17$ & 0.407 & 6.27 & 81.47 & 45578.35 & 3.62 \\
\hline $33-18$ & 0.416 & 6.52 & 83.88 & 48074.54 & \\
\hline
\end{tabular}

